\title{
Microarray analyses and molecular profiling of steatosis induction in immortalized human hepatocytes
}

\author{
Andrea De Gottardi ${ }^{1}$, Manlio Vinciguerra², Antonino Sgroi ${ }^{1}$, Moulay Moukil $^{2}$, Florence Ravier-Dall'Antonia', \\ Valerio Pazienza ${ }^{1}$, Paolo Pugnale ${ }^{1}$, Michelangelo Foti ${ }^{2}$ and Antoine Hadengue ${ }^{1}$
}

Hepatic steatosis is an important risk factor for the development of inflammation, fibrosis and impaired liver regeneration. The factors regulating lipid accumulation and driving hepatic steatosis toward inflammation, fibrosis and impaired regeneration are largely unknown. The aim of this study was to identify major alterations in gene expression occurring in steatotic hepatocytes, and to analyze how these changes impact cellular processes associated with steatosis. Microarray gene chips and RT-PCR were performed to analyze changes in gene expression induced in fatty human immortalized hepatocytes after treatment with $50 \mu \mathrm{M}$ oleic acid for 7 days. Lipid metabolism and triglyceride accumulation in these cells was examined by Oil-Red-O staining, thin-layer chromatography (TLC) and immunofluorescence. Caspase 3 activity, BrdU incorporation and trypan blue exclusion were used to study apoptosis, proliferation and cell viability. Finally, quantitative analysis of signalling induced by insulin was performed by Western blot. Characterization of steatosis in three hepatocyte-derived cell lines indicated that the immortalized human hepatocytes $(\mathrm{IHH})$ line was the most appropriate cell line for this study. Gene expression analysis showed significant alterations in the transcription of two major classes of genes involved either in cholesterol and fatty acid biosynthesis, as well as lipid export, or in apoptosis and cell proliferation. Such changes were functionally relevant, since TLC indicated that synthesis and accumulation of triglycerides were increased in steatotic cells, while synthesis of cholesterol and fatty acids were decreased. Lipid accumulation in IHH was associated with an increased apoptosis and an inhibition of cell proliferation and viability. No detectable changes in genes associated with insulin resistance were observed in steatotic cells, but signalling induced by insulin was more efficient in steatotic IHH as compared to control cells. We conclude that IHH represent a new valuable model of steatosis, not associated with insulin resistance, to study at both the genetic and functional level factors involved in the process of lipid accumulation and steatosis-associated liver injury.

Laboratory Investigation (2007) 87, 792-806; doi:10.1038/labinvest.3700590; published online 11 June 2007

KEYWORDS: fatty liver disease; immortalized human hepatocytes; insulin signaling; lipid metabolism; microarrays; steatosis

Obesity, as part of the metabolic syndrome, constitutes one of the major risk factors for the development of fatty liver, a condition also known as steatosis. ${ }^{1-3}$ Until recently, hepatic steatosis was regarded as inconsequential, but increasing evidence suggests that a fatty liver is more vulnerable to factors that lead to inflammation and fibrosis. ${ }^{4}$ The fact that obesity and steatosis may negatively influence the course of other liver diseases, for example viral hepatitis, ${ }^{5,6}$ has important therapeutic implications, because a reduction in steatosis may improve liver injury and decrease the progression of fibrosis. This is supported by the observation that weight reduction in patients with chronic hepatitis $\mathrm{C}$ may significantly reduce fibrosis and stellate cell activation. ${ }^{7}$
Under the influence of as yet largely unknown factors, steatosis can progress to steatohepatitis (ie, the association of lipid overload and inflammation) and fibrosis. Once the end stage of fibrosis (also called cirrhosis) develops in patients with non-alcoholic fatty liver disease (NAFLD), the mortality rate increases significantly ${ }^{8}$ and the prognosis appears to be poor, with studies reporting high rates of hepatocellular carcinoma. $^{9}$

A common feature of patients with NAFLD is an excess of circulating free fatty acids (FFAs). One likely cause of hepatic steatosis is an increased influx of FFA into hepatocytes, which generally occurs through membrane diffusion. Upon entry into the cell, FFAs are rapidly modified by acyl-CoA

\footnotetext{
${ }^{1}$ Division of Gastroenterology and Hepatology, Faculty of Medicine, University of Geneva, Geneva, Switzerland and ${ }^{2}$ Department of Cell Physiology and Metabolism, Faculty of Medicine, University of Geneva, Geneva, Switzerland

Correspondence: Dr A De Gottardi, MD, PhD, Division of Gastroenterology and Hepatology, University Hospital, Rue Micheli-du-Crest 24, 1205 Geneva 14, Switzerland. E-mail: andrea.degottardi@hcuge.ch
} 
synthetases and are no more available for transport or diffusion. The majority of excess FFA is then converted to triglycerides and stored in lipid droplets. ${ }^{10}$ Also, the lipid export from the liver may be impaired in NAFLD, because of defective incorporation of triglyceride into apolipoprotein $\mathrm{B}$ (apoB) or reduced apoB synthesis, or excretion. ${ }^{11,12}$

Hepatic steatosis may progress toward fibrosis due to liver damage caused by increased lipid peroxidation and oxygen reactive species. In NAFLD, one component of lipid peroxidation is excess substrate, represented by triglyceride droplets in hepatocytes. ${ }^{10}$ The consequences of lipid accumulation are an increased DNA oxidative damage and cell death. ${ }^{13}$ Additionally, an increased delivery of fatty acids to the liver results in an induction of CYP2E1, leading to an increased formation of reactive oxygen species, which may directly contribute to the activation of stellate cells, the main effectors of fibrosis in the liver. ${ }^{14,15}$

Another important feature of fatty liver disease is its association with insulin resistance, although this feature seems to depend on the etiology of steatosis. ${ }^{16-19}$ In favor of a link between insulin resistance and steatosis, hyperinsulinemia has been shown to promote de novo lipogenesis by upregulating lipogenic transcription factors such as sterol regulatory binding protein-1c (SREBP-1c) and carbohydrate response element binding protein. ${ }^{20-22}$ Insulin-mediated activation of SREBP-1c increases in turn malonyl-CoA, which inhibits FFA oxidation, thereby favoring hepatic triglyceride accumulation. Hepatic insulin resistance may also be associated with a decreased expression of insulin receptor substrate (IRS) proteins, which have been shown to modulate lipid metabolism, as demonstrated by the increase of liver triglycerides in the single or dual IRS1/IRS2 knockdown in mice. ${ }^{23}$

An additional feature of NASH and HCV infection-related steatosis, is the presence of hepatocyte apoptosis, which is associated with increased levels of activated caspases 3 and $7,{ }^{24}$ and a decreased expression of the anti-apoptotic factor $\mathrm{Bcl}-2 .{ }^{25}$ Also, hepatocyte regeneration has been shown to be impaired in human fatty liver, through a mechanism involving oxidative stress and hepatic progenitor cells. ${ }^{26}$

The genome-wide expression changes related to the presence of steatosis have been investigated by some authors in the whole liver, ${ }^{27-29}$ but comparative data from normal and steatotic human hepatocytes are not available. We report here the results from gene expression analyses, as well as investigations of metabolic dysfunctions, in fatty human immortalized hepatocytes. These data not only confirm previously identified features characterizing the fatty liver in vivo, but also provide new candidate genes potentially implicated in metabolic syndromes associated with hepatic steatosis. Our study also validates immortalized human hepatocytes ( $\mathrm{IHH})$ as a novel in vitro model to investigate the mechanisms and consequences of lipid accumulation in hepatocytes, independently of insulin resistance.

\section{MATERIALS AND METHODS \\ Cell Culture}

Human hepatocytes, isolated and immortalized by lentiviral transduction with the SV40T antigen and hTERT as previously described $(\mathrm{IHH}),{ }^{30}$ were a kind gift from Professor Didier Trono and Dr Tuan Nguyen. IHH were maintained at $37^{\circ} \mathrm{C}$ and $5 \% \mathrm{CO}_{2}$ in phenol red-free Dulbecco's modified Eagle's medium (DMEM/F-12) (GIBCO-BRL) containing $1 \times 10^{-6} \mathrm{M}$ dexamethasone, $1 \times 10^{-12} \mathrm{M}$ human insulin (Humalog, Lilly) and antibiotics $(100 \mathrm{IU} / \mathrm{ml}$ penicillin, $100 \mathrm{mg} / \mathrm{ml}$ streptomycin) with $10 \%$ fetal bovine serum (FBS) (Invitrogen). This medium composition was defined as 'normal condition'. Induction of steatosis was obtained by using a $100 \mathrm{mM}$ oleic acid (Sigma) stock solution diluted in ethanol, which was added to the normal condition culture medium in order to obtain a final concentration of $50 \mu \mathrm{M}$. The duration of this treatment was 7 days. To normal condition cultures were added the same volume of ethanol, which was maintained at less than 1:1000. Two other liver cell lines, Huh-7 and Hep G2 (European Collection of Cell Cultures, ECACC), were cultured in the same conditions containing equal concentrations of dexamethasone, insulin, antibiotics and FBS.

\section{Affymetrix Analysis}

Total RNA was isolated and processed from $10^{6}$ cells using the RNeasy extraction kit (Qiagen), according to the manufacturer's protocol. Only high-quality RNA with intact $18 \mathrm{~S}$ and $28 \mathrm{~S}$ RNA was used for the synthesis of biotin-labelled cRNA and for its hybridization to human HG-U133A chips (Affymetrix). For each condition, three chips, containing 54675 distinct transcripts each, were hybridized and scanned. The fluorescence signals were analyzed with the Affymetrix software MAS 5.0 and DMT 3.0., which calculated signal values and provided detection calls (present, marginal or absent) for each probe set. Detection calls were determined from statistical calculations of the difference in hybridization signals between perfect match oligonucleotides and their corresponding control mismatch sequence (probe set).

IHH samples were prepared in triplicate for both normal conditions and steatosis. Each of the experimental control samples was compared with each of the steatosis samples, resulting in nine pairwise comparisons. This approach, which is based on the Welch- $t$ test, allows the ranking of results by concordance and provides an estimate of the significance ( $P$-value) of each identified change in gene expression. Transcripts were considered to be differentially expressed, if their levels changed in the same direction in at least seven out of nine comparisons, and if the $P$-value for the median relative change was $<0.05$. Results are expressed as the average relative change in the comparisons.

So-called focus genes, defined by significant differential expression in at least seven out of nine probe set comparisons, were used as the starting point for generating biologic networks. Ingenuity Pathways Analysis (IPA) software was 
used to identify key functions and pathways differentially regulated between normal and steatotic IHH.

\section{Quantitative Real-Time PCR}

Single-stranded cDNA templates for real-time PCR analysis were synthesized from the same RNA pools used for the microarray analysis, and from independently derived and extracted secondary samples. Specific forward and reverse primers were designed using Primer Express 2.0 software (Applied Biosystems). The sequences are given as Supplementary Information on the Laboratory Investigation web site. Primer pairs were tested and efficiencies were measured using standard curves from serial dilutions of cDNA. Specificity of Sybr Green reactions was determined by examination of product melting curves. cDNA was PCR amplified in a 7900HT SDS System (Applied Biosystems) and raw threshold-cycle $\left(C_{\mathrm{t}}\right)$ values were obtained from SDS 2.0 software (Applied Biosystems). Relative quantities (RQ) were calculated using the formula $R Q=E-C_{\mathrm{t}}$, using efficiencies (E) calculated for each run with the DART-PCR algorithm, as described. ${ }^{31}$ A mean quantity was calculated from triplicate PCR reactions for each sample, and this quantity was normalized to two similarly measured quantities of normalization genes (EEF1A1 and TBP). Normalized quantities were averaged for three replicates for each data point and are presented as the mean \pm s.d. The highest normalized relative quantity was arbitrarily designated as a value of 1.0. Fold changes were calculated from the quotient of means of these normalized quantities. The statistical significance of fold changes was determined by a paired Student's $t$-test. Primer sequences are provided in Supplementary Table S1.

\section{Microscopy}

Semi-confluent IHH grown on a coverslip were fixed in buffered formaldehyde $4 \%$ for $20 \mathrm{~min}$ at room temperature. Staining of intracellular neutral lipids was performed with Oil-red-O (Sigma): the positively stained area was quantified using Metamorph Professional Image Analysis software (Universal Imaging). Intracellular neutral fats were also labelled with $200 \mathrm{nM}$ BODIPY 505/515 (Invitrogen) for $30 \mathrm{~min}$. After washing with phosphate-buffered saline (PBS), coverslips were placed on microscopy slides and they were observed using a fluorescence microscope (Zeiss Axiocam Imaging).

\section{Flow Cytometry}

For flow cytometry, a suspension of IHH with $200 \mathrm{nM}$ BODIPY 505/515 was incubated in PBS for $30 \mathrm{~min}$ at $37^{\circ} \mathrm{C}$ in the dark. After washing with PBS, flow cytometry was performed using FACS-Calibur (Becton-Dickinson).

\section{Triglyceride Assay}

Triglycerides were extracted from $5 \times 10^{5}$ cells previously treated with oleic acid (50 $\mu \mathrm{M}$ for 7 days) and control cells, according to the Folch method, ${ }^{32}$ using as organic solvent chloroform/methanol (2:1 v/v, Folch reagent). A triglyceride assay kit (Sigma) was used for quantification, using a spectrophotometer with absorbance at $540 \mathrm{~nm}$ according to the manufacturer's instructions.

\section{TLC}

For lipid extraction, cells were disrupted by addition of lysis buffer (Tris-HCl 50 mM, pH 8, NaCl 150 mM, Triton X 1\%) and the protein concentration of the lysate was measured. After a $30 \mathrm{~min}$ incubation of $100 \mu \mathrm{g}$ proteins in $800 \mu \mathrm{l}$ distilled water, $2 \mathrm{ml}$ methanol, $1 \mathrm{ml}$ chloroform, $1 \mathrm{ml}$ chloroform and $1 \mathrm{ml}$ PBS were added to the solution and incubated for another $10 \mathrm{~min}$ on ice. Then, samples were centrifuged $\left(200 \mathrm{~g}, 4^{\circ} \mathrm{C}, 5 \mathrm{~min}\right.$.) and the lipid phase was removed and dried under nitrogen flux in a glass tube. ${ }^{33}$ Lipid samples were re-dissolved in $30 \mu \mathrm{l}$ chloroform/methanol (2:1, by vol) and transferred on a TLC plate (Silica gel G $6010 \times 10 \mathrm{~cm}$, Merck) with a microcapillary. TLC plates were then placed in the developing chamber for solvent migration. The eluting solvent used was a mixture of hexane/diethyl ether/formic acid (80:20:2, by vol). Lipid spots were visualized after treatment with $3 \%$ cupric acetate, $8 \%$ phosphoric acid reagent and heating at $160^{\circ} \mathrm{C}$ for $10-15 \mathrm{~min}$. Finally, plates were scanned with a densitometer operated in the reflectance mode and spots were quantified by integration of variable pixel intensities on ImageQuant analysis software (GE Healthcare). To measure de novo lipogenesis, $2 \times 10^{6}$ cells were incubated in the presence of $1 \mathrm{mM}\left[2-{ }^{14} \mathrm{C}\right]$ acetate ( $5 \mu \mathrm{Ci}$, Moravek Biochemicals) for $4 \mathrm{~h}$ at $37^{\circ} \mathrm{C}$. Cells were then washed twice with PBS and lipids were extracted and separated by TLC, as described above. TLC plates were exposed to a storage phosphor screen (Molecular Dynamics) during $48 \mathrm{~h}$ and scanned with a Typhoon 9400 phosphoimager (Amersham).

\section{Apoptosis, Cell Viability and Proliferation Assay}

Apoptosis was assessed by measuring the caspase 3 activity, using a specific assay (Roche). Briefly, $2 \times 10^{6} \mathrm{IHH}$ were lysed in $200 \mu \mathrm{l}$ lysis buffer, vortexed and incubated for $1 \mathrm{~min}$ on ice. After centrifugation at maximum speed in a table-top centrifuge for $15 \mathrm{~min}, 100 \mu \mathrm{l}$ of the supernatant were added on a microtiter plate pre-coated with anti-caspase- 3 monoclonal antibodies and incubated at $37^{\circ} \mathrm{C}$ for $60 \mathrm{~min}$. After washing, $100 \mu \mathrm{l}$ of caspase 3 substrate solution were added, and after an incubation of $120 \mathrm{~min}$, the caspase 3 enzymatic activity was measured fluorometrically.

The trypan blue exclusion assay was used to determine the viability of steatotic and control $\mathrm{IHH}$, using a hemocytometer. In brief, $10 \mu \mathrm{l}$ of $0.4 \%$ trypan blue in PBS (pH 7) was added into $90 \mu \mathrm{l}$ of cell suspension. A $10 \mu \mathrm{l}$ volume of this mixture was placed on the hemocytometer for counting trypan blue-stained cells under the microscope. More than 100 cells per field were examined and data are expressed as percent of dead cells \pm s.d. 
Cell proliferation was measured using the BrdU incorporation assay (Roche). A total of $5 \times 10^{4}$ cells were added to a 96-well microtiter plate and pulse labelled with $\mathrm{BrdU}$ for $6 \mathrm{~h}$. After fixation and DNA denaturation, a peroxidaseconjugated anti-BrdU antibody was added and incubated for $60 \mathrm{~min}$. After washing, a peroxidase substrate was added and absorbance was measured in an ELISA plate reader.

\section{Protein Analysis}

Control and steatotic $\mathrm{IHH}$ were serum starved $12 \mathrm{~h}$ and incubated with $10^{-7} \mathrm{M}$ insulin (Novo Nordisk) at $37^{\circ} \mathrm{C}$ for different times. After insulin stimulation, cells were immediately washed with cold PBS and frozen with liquid nitrogen to stop signalling events. Cells were then lysed in cold RIPA buffer $(50 \mathrm{mM}$ Tris- $\mathrm{HCl} \mathrm{pH} 7.5,150 \mathrm{mM} \mathrm{NaCl}$, $1 \%$ NP-40, $0.5 \%$ sodium deoxycholate, $0.1 \%$ SDS) including $10 \mathrm{mM} \mathrm{NaF}, 5 \mathrm{mM}$ ortho-vanadate and a cocktail of protease inhibitors (Roche). Equal amounts of proteins for each sample were resolved on 10\% SDS acrylamide gels and blotted onto nitrocellulose membranes (Amersham Biosciences) for Western blots. Antibodies against insulin receptor, phospho-insulin receptor, IRS1 and phospho-IRS1 (Tyr632) were from Santa Cruz Biotechnology. Antibodies against phospho-IRS1 (Ser636/9), Akt, phospho-Akt (Thr308 and Ser473), ERK1/2 and phospho-ERK1/2 (Thr202 and Tyr204) were from Cell Signaling Technology. Primary antibodies were detected using appropriated HRP-conjugated secondary antibodies from Bio-Rad and the enhanced chemiluminescence detection system (ECL, Amersham). Quantifications were performed using the ChemiDoc XRS and the Quantity One software (Bio-Rad).

\section{Statistics}

All results are presented as mean \pm s.d. of experiments performed in triplicate. Results of two groups were compared using the Student's $t$-test. Pairwise comparisons were performed in microarray studies using the Welch- $t$ test. $P<0.05$ was considered statistically significant.

\section{RESULTS}

\section{Induction of Steatosis in Hepatocyte Cell Lines}

The clinical criteria used to diagnosis steatosis on histological sections of human livers is the visible accumulation of lipid droplets in more than $5 \%$ of hepatocytes. ${ }^{34}$ Since our interest was to identify dysregulated genes in fatty hepatocytes compared with normal ones, our first step has been to identify an adequate cell model. To this end, we induced steatosis in IHH and in the tumor-derived cell lines Hep G2 and Huh-7. Monounsaturated oleic acid was used to induce steatosis, since it was more efficient than palmitic acid (saturated) or arachidonic acid (polyunsaturated) (data not shown). Under normal cell culture conditions, Oil-red-O staining revealed that IHH contain a very low amount of intracellular neutral lipids. After treatment with oleic acid, IHH accumulated cytoplasmic lipid droplets, mainly distributed in small vesicles (Figure 1a and b). In contrast to $\mathrm{IHH}$, both Huh-7 and Hep G2 cells displayed an important Oil-red-O staining already in normal cell culture conditions (Figure 1a, c and e). TLC analysis of the lipid content of the three cell lines cultured in the absence of oleic acid indeed showed that these differences were mainly due to an increase in intracellular triglyceride content and, although only partially, in fatty acids, whereas intracellular cholesterol content did not change significantly among the three cell lines (Figure 1g). Since in normal culture conditions IHH contain very few visible intracellular lipid droplets, we considered that these cells were closer than Hep G2 and Huh-7 to what is observed in healthy human hepatocytes and we focused our subsequent analyses on this cell line.

To further confirm the accumulation of neutral lipids in IHH treated with oleic acid, we stained cells using BODIPY 505/515. Similar to the Oil-red-O staining, oleic acid-treated IHH showed an intense fluorescent signal corresponding to steatosis distributed in small cytoplasmic vesicles, while only very few fluorescent areas were seen in normal IHH (Figure $2 a$ and $b)$. To quantify the accumulation of neutral lipids in fatty IHH, cells stained with BODIPY 505/515 were then analyzed by FACS. Fluorescence of IHH increased from $3.3 \pm 2.1$ in control cells to $52.3 \pm 36.1$ arbitrary fluorescence units in steatotic hepatocytes (Figure 2c), thus corresponding to a 16-fold increase in lipid accumulation induced by oleic acid treatment. Steatotic hepatocytes were also increased in size and in granularity, as demonstrated by a shift to the right in the forward scatter axis and an upward displacement along the side scatter axis after oleic acid treatment (Figure $2 \mathrm{~d}$ and $\mathrm{e})$.

\section{Lipid Metabolism in Steatotic IHH}

To further characterize the type of neutral lipid accumulated into fatty hepatocytes following oleic acid treatment, the content and biosynthesis of neutral lipids in IHH exposed or not to oleic acid was examined by TLC. Consistent with our flow cytometry analysis, steatosis induced by oleic acid was associated with an 18-fold increase in the total amount of intracellular triglycerides (Figure 3a). The cellular content of cholesterol, cholesterol esters and fatty acids was unchanged. We then assessed the biosynthesis of neutral lipids by exposing the cells to $\left[2-{ }^{14} \mathrm{C}\right]$ acetate and performing TLC followed by autoradiography (Figure 3c). Quantifications of these data showed that biosynthesis of triglycerides was increased by 2.2 -fold in steatotic IHH, whereas a decrease was measured for fatty acids and cholesterol $(-5.1-$ and -7.5 -fold, respectively).

Taken together, these data show that IHH treated with oleic acid develop steatosis by increasing their triglyceride synthesis, and that the decreased synthesis of cholesterol and fatty acids does not significantly affect intracellular triglyceride content in steatotic cells. 

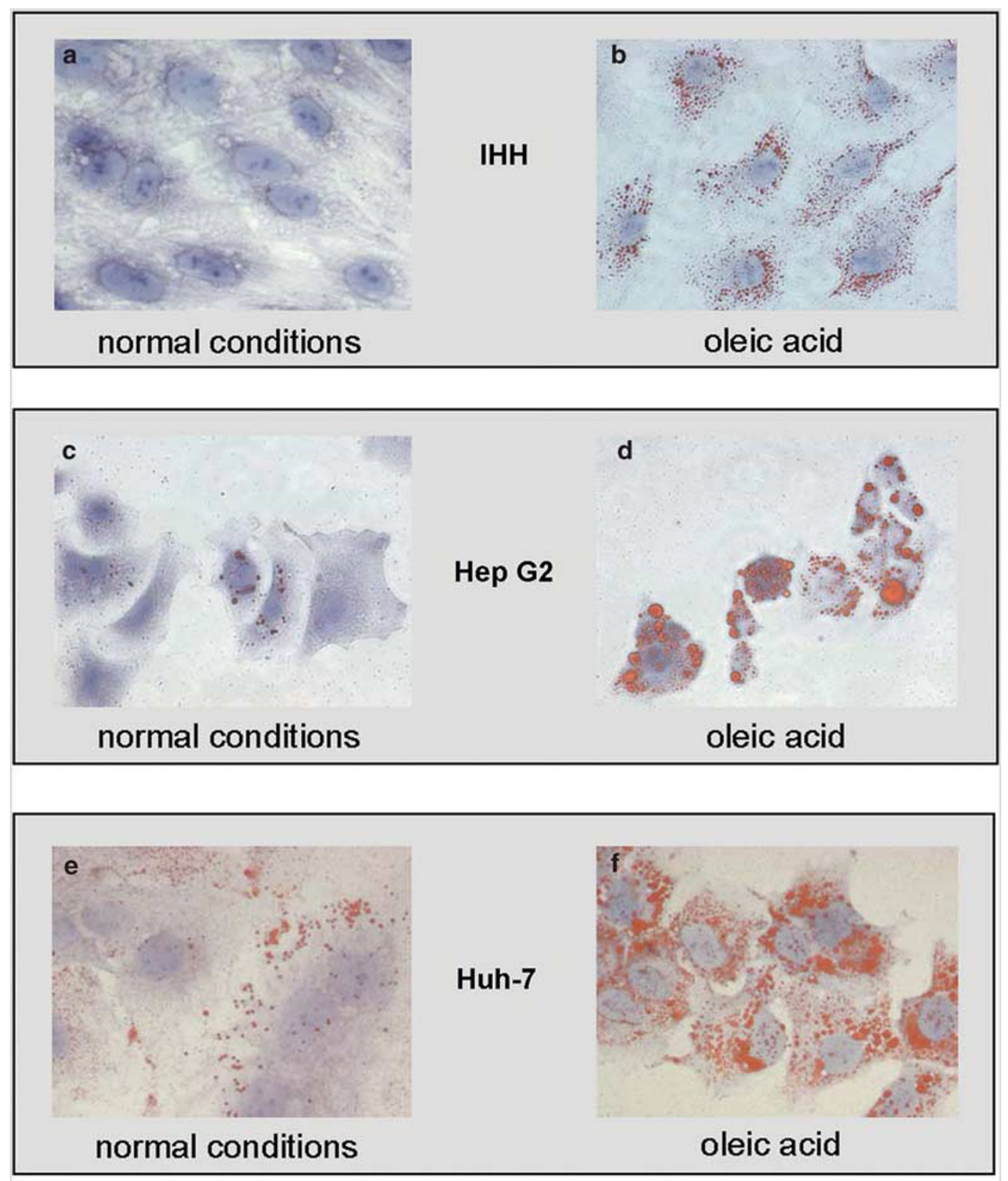

\section{g}

Triglycerides

Fatty acids

Cholesterol
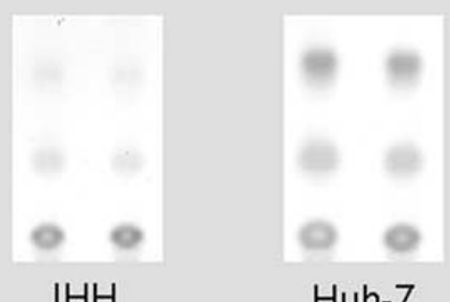

Huh-7

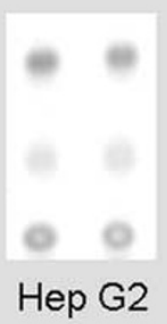

Figure 1 Induction of steatosis by oleic acid in human hepatocyte-derived cell lines. IHH (a, b), Hep G2 (c, d) and Huh-7 (e, f) cells were incubated 7 days in the presence of $50 \mu \mathrm{M}$ of oleic acid in the culture medium to produce steatosis. Lipid droplet accumulation was visualized by Oil-Red-O staining and counterstained with hematoxylin. Original magnification is $\times 200$. (g) Detection of intracellular neutral lipids in normal culture conditions by TLC in IHH, Huh-7 and Hep G2 cells. 


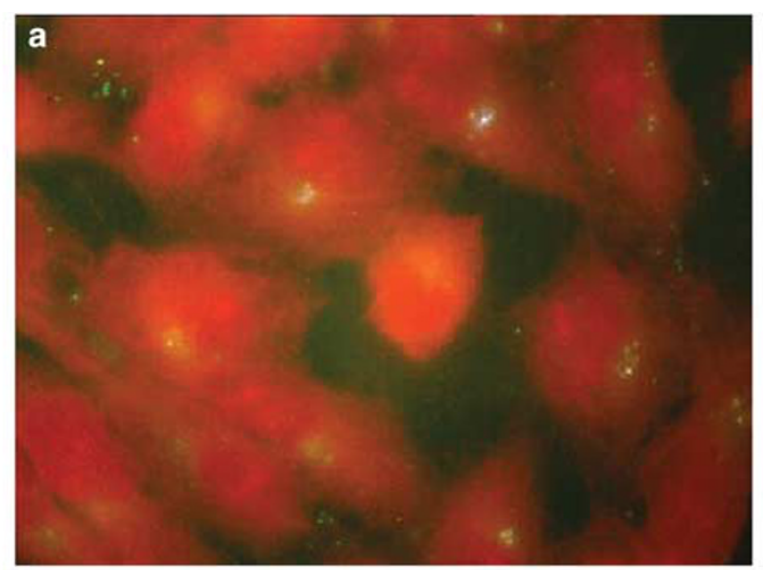

normal conditions

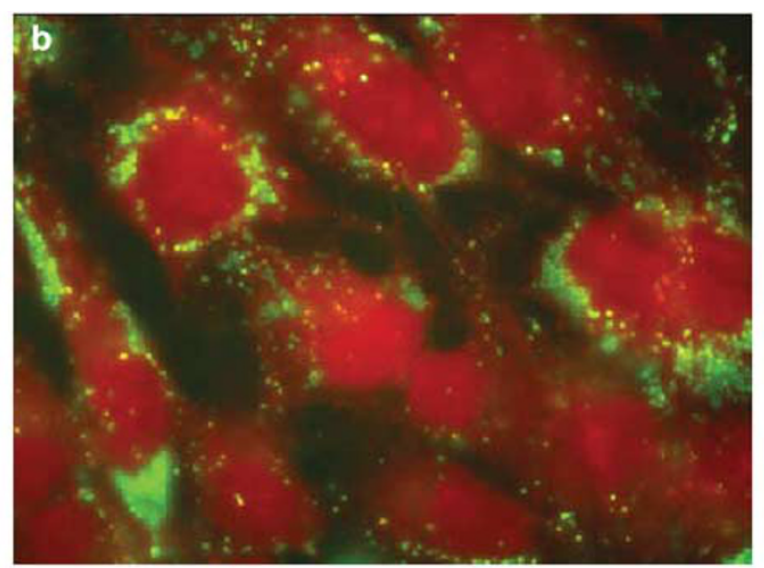

oleic acid

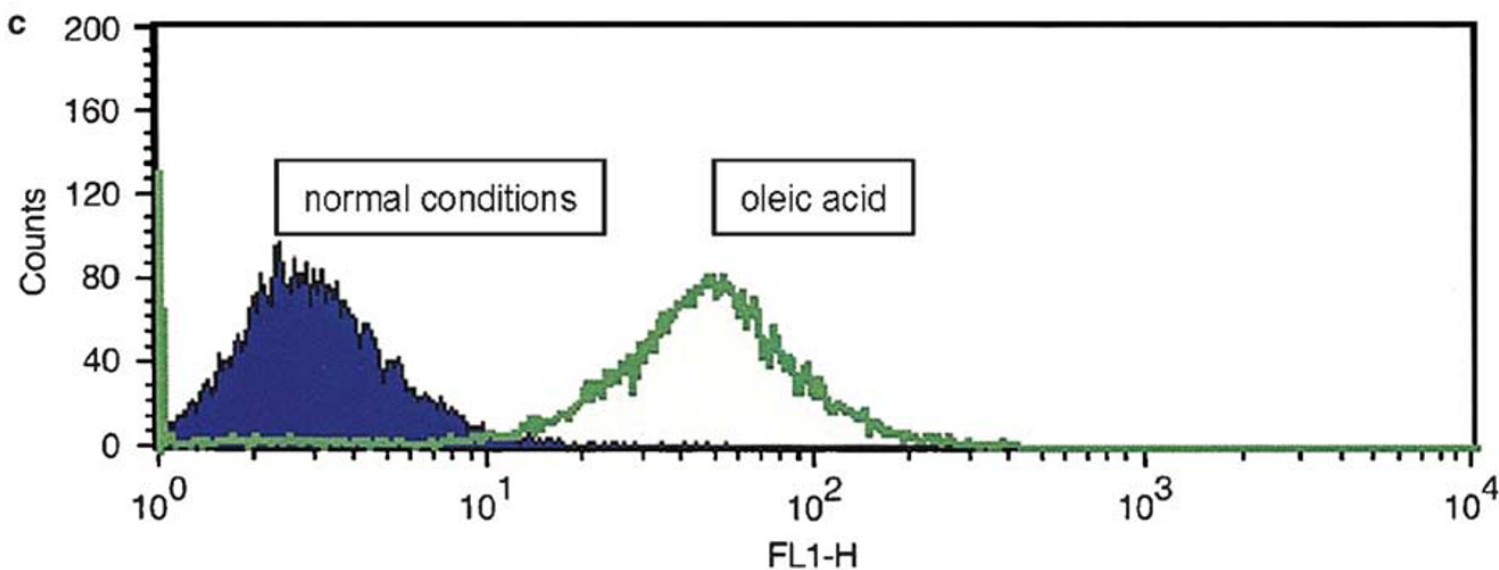

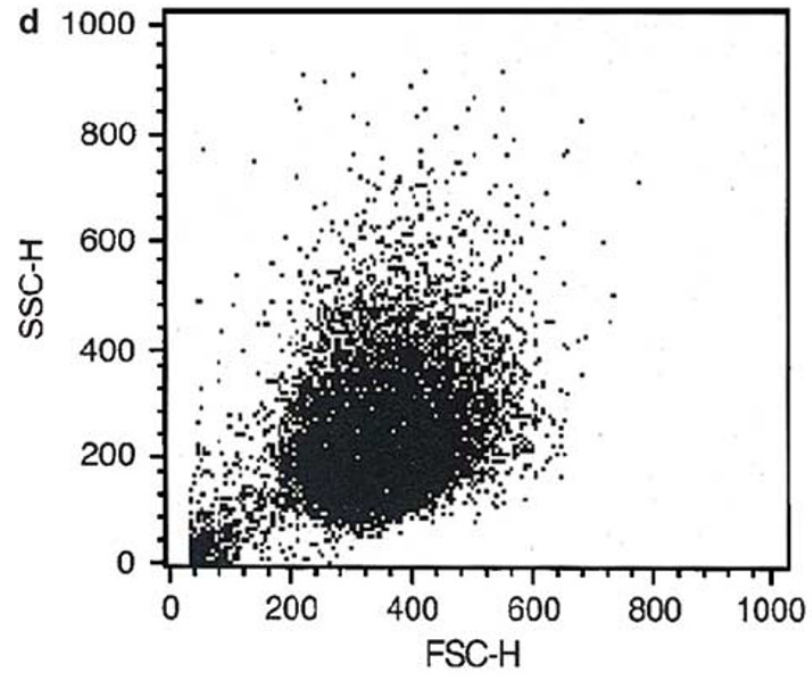

normal conditions

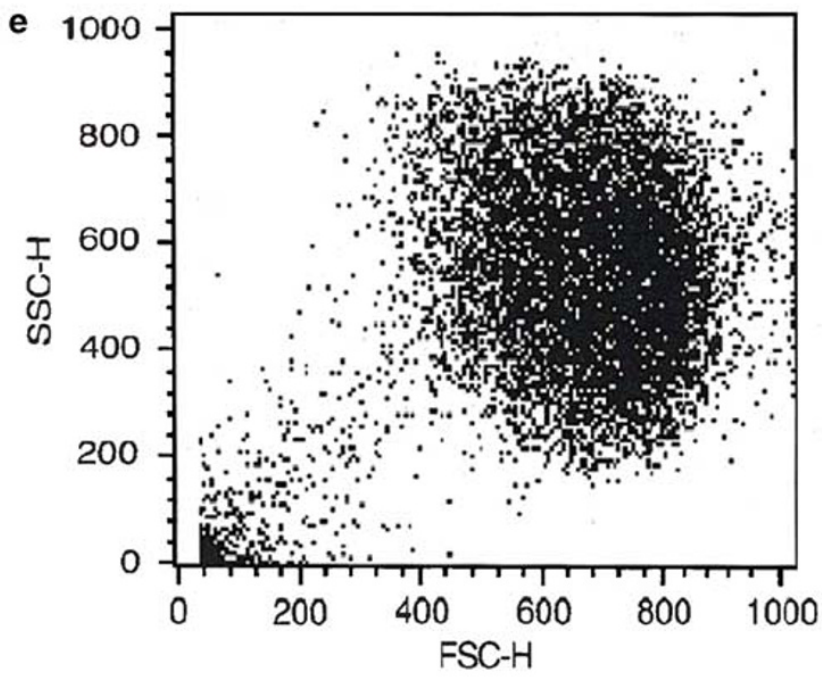

oleic acid

Figure 2 Visualization and flow cytometry analysis of neutral lipid accumulation in oleic acid-treated IHH. (a, b) IHH were labelled with the neutral lipid marker BODIPY 505/515, $200 \mathrm{nM}$ for $30 \mathrm{~min}$ after treatment with oleic acid $50 \mu \mathrm{M}$ for 7 days and steatosis was assessed by epifluorescence. (c) Representative flow cytometry analysis of BODIPY 505/515 fluorescence in control and steatotic $\mathrm{IHH}$. (d, e) Representative flow cytometry analysis of the cell size (forward scatter) and cell granularity (side scatter) in $\mathrm{IHH}$ treated or not with oleic acid. 
a

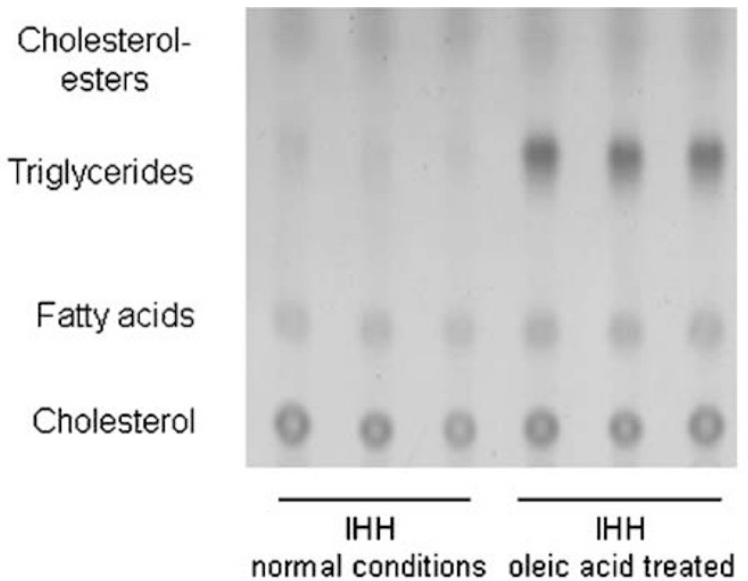

b

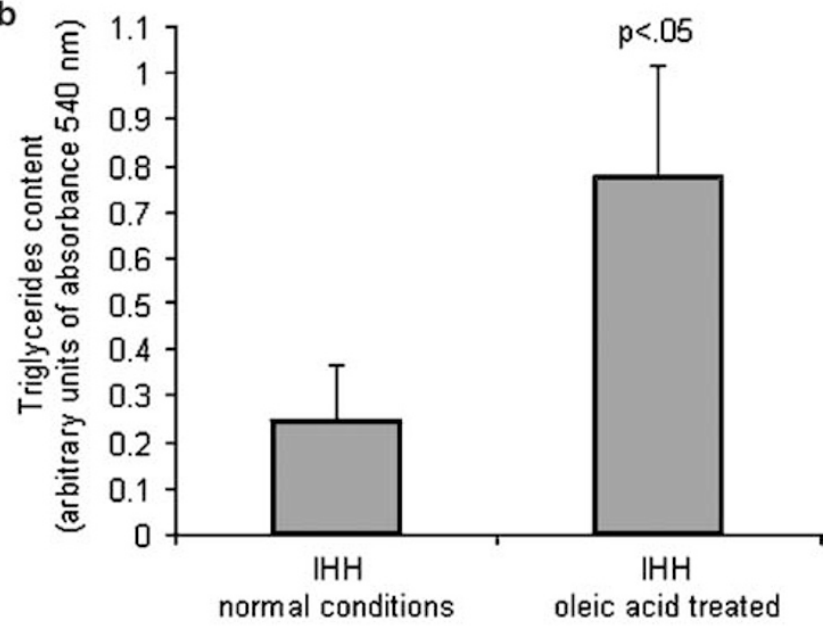

c

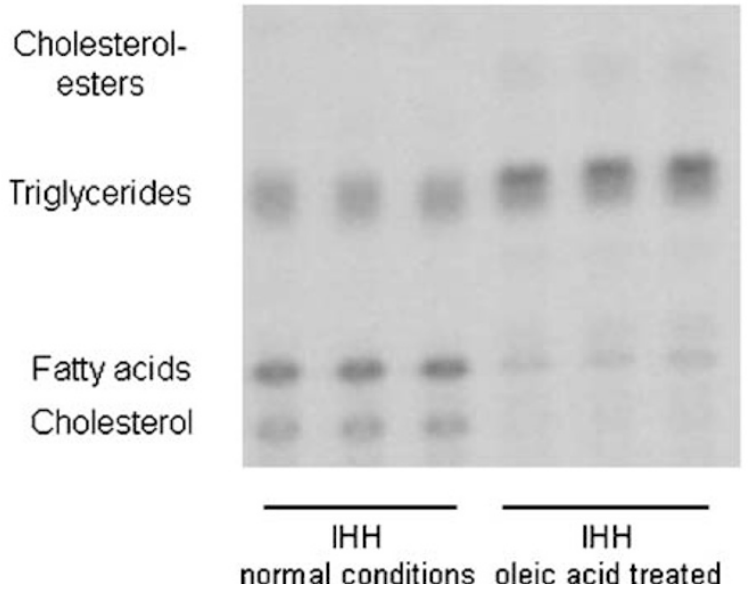

Figure 3 Analysis of lipid content and biosynthesis in $\mathrm{IHH}$ exposed or not to oleic acid. (a) Representative TLC of neutral lipids content in normal and steatotic IHH. Data are representative TLC analyses of two independent experiments (b) Quantification of the triglyceride content in normal and steatotic $\mathrm{IHH}$. Data are means \pm s.d. of two independent experiments. (c) Phosphoimager analysis of newly sythesized, radiolabelled neutral lipids, separated by TLC in control and steatotic IHH. Representative examples of lipid detection by TLC show triplicate signals for each condition.

\section{Microarray Analysis and Quantitative PCR}

To study the effects of oleic acid treatment on the expression of genes regulating lipid metabolism and other cellular processes, gene expression was analyzed in normal and in steatotic IHH, using the microarray technology. Our data indicated that when stringent criteria were applied (ie, an expression change $>2$-fold, Welch- $t$ test $P$-value $<0.05$, and at least seven concordant comparisons out of nine), steatotic IHH exhibited 30 differentially expressed genes. There were 12 genes with a significant increased expression and 18 genes, which were downregulated (Table 1).

To obtain a functional classification of the observed changes, we introduced differentially expressed genes into the IPA software, which built up several groups of genes according to their major biological functions as shown in Table 2. According to our morphological observations, expression of genes involved in the regulation of lipid metabolism was significantly altered in steatotic IHH. In addition, genes regulating apoptosis and cell proliferation, as well as genes controlling the intracellular redox balance were also substantially dysregulated.

With respect to the lipid metabolism, our microarray analyses were consistent with our biochemical data (Figure 3 ), since they suggested that the decrease of fatty acid and cholesterol biosynthesis in steatotic IHH might be the result of a genetic repression of key enzymes involved in these processes. Indeed, the expression of sterol regulatory element binding protein 1, which is a key factor in the control of fatty acid synthesis tended to be decreased $(-3.47$-fold) in steatotic cells (but was not included in the 30 differentially expressed genes in Table 1, since only five out of nine comparisons were concordant). Similarly, fatty acid synthase and stearoyl-CoA desaturase genes were downregulated by 2.01- and 3.51-fold, respectively. The decreased expression of several enzymes regulating the biosynthesis of cholesterol (Table 2) was also in line with the results of TLC, indicating a reduced production of cholesterol in steatotic hepatocytes. The expression of enzymes involved in the biosynthesis of triglycerides was not significantly changed, suggesting that their increased biosynthesis in steatotic IHH is not due to a genetic upregulation of enzymes directing these processes, but rather to an excess of substrate or an upregulated activity. To validate our microarray analysis, changes in the expression of nine of the genes presented in Table 2, which are key players in biological processes affected by lipid accumulation in IHH, were further examined by RT-PCR (right column, Table 2). RT-PCR analyses of these genes in normal and steatotic IHH confirmed the alterations measured in microarray experiments.

\section{Cellular Apoptosis, Proliferation and Viability}

In some clinical conditions, such as chronic HCV infection or NASH, the presence of steatosis may be associated with a dysregulated cellular apoptosis and/or proliferation. Several genes controlling apoptotic and proliferative mechanisms 
Table 1 Differential gene expression in steatotic immortalized human hepatocytes

\begin{tabular}{|c|c|c|c|}
\hline $\begin{array}{l}\text { Gene } \\
\text { symbol }\end{array}$ & Description & Representative ID & $\begin{array}{c}\text { Fold } \\
\text { change }\end{array}$ \\
\hline CSTA & Cystatin A (stefin A) & NM_005213 & 3.47 \\
\hline AKR1C2 & $\begin{array}{l}\text { Aldo-keto reductase family 1, member C2 (dihydrodiol dehydrogenase 2; bile acid binding protein; } \\
\text { 3-alpha hydroxysteroid dehydrogenase, type III) }\end{array}$ & M33376 & 2.83 \\
\hline SERPINA3 & Serine (or cysteine) proteinase inhibitor, clade A (alpha-1 antiproteinase, antitrypsin), member 3 & NM_001085 & 2.58 \\
\hline ASNS & Asparagine synthetase & NM_001673 & 2.57 \\
\hline AKR1C1 & $\begin{array}{l}\text { Aldo-keto reductase family } 1 \text {, member C1 (dihydrodiol dehydrogenase } 1 \text {; } \\
\text { 20-alpha (3-alpha)-hydroxysteroid dehydrogenase) }\end{array}$ & S68290 & 2.54 \\
\hline GLIPR1 & GLI pathogenesis-related 1 (glioma) & NM_006851 & 2.14 \\
\hline MT2A & Metallothionein 2A & NM_005953 & 2.02 \\
\hline PTX3 & Pentraxin-related gene, rapidly induced by IL-1 beta & NM_002852 & 2.01 \\
\hline MT1X & Metallothionein $1 \mathrm{X}$ & NM_002450 & 2.01 \\
\hline
\end{tabular}

Downregulated genes

\begin{tabular}{|c|c|c|c|}
\hline HMGCS1 & 3-Hydroxy-3-methylglutaryl-Coenzyme A synthase 1 (soluble) & NM_002130 & -6.17 \\
\hline SCD & Stearoyl-CoA desaturase (delta-9-desaturase) & AB032261 & -3.51 \\
\hline SQLE & Squalene epoxidase & AF098865 & -2.58 \\
\hline IDI1 & Isopentenyl-diphosphate delta isomerase 1 & BC005247 & -2.56 \\
\hline DHCR7 & 7-Dehydrocholesterol reductase & NM_001360 & -2.40 \\
\hline LDLR & Low-density lipoprotein receptor (familial hypercholesterolemia) & NM_000527 & -2.40 \\
\hline INSIG1 & Insulin-induced gene 1 & BG292233 & -2.36 \\
\hline PEG10 & Paternally expressed 10 & BE858180 & -2.30 \\
\hline MYLIP & Myosin regulatory light chain interacting protein & NM_013262 & -2.25 \\
\hline CYP51A1 & Cytochrome P450, family 51 , subfamily A, polypeptide 1 & U40053 & -2.22 \\
\hline ACAT2 & Acetyl-Coenzyme A acetyltransferase 2 (acetoacetyl-Coenzyme A thiolase) & BC000408 & -2.22 \\
\hline EDIL3 & EGF-like repeats and discoidin I-like domains 3 & NM_005711 & -2.21 \\
\hline HMGCR & 3-Hydroxy-3-methylglutaryl-Coenzyme A reductase & NM_000859 & -2.21 \\
\hline ACTR2 & ARP2 actin-related protein 2 homolog (yeast) & AA699583 & -2.17 \\
\hline THBS1 & Thrombospondin 1 & BF055462 & -2.15 \\
\hline IL7R & Interleukin 7 receptor /// interleukin 7 receptor & NM_002185 & -2.14 \\
\hline COL4A3 & Collagen, type IV, alpha 3 (Goodpasture antigen) & Al694562 & -2.10 \\
\hline KIAA1333 & KIAA1333 & AA887053 & -2.07 \\
\hline
\end{tabular}

resulted up- or downregulated in the microarray studies and by RT-PCR (Table 2). We thus investigated whether these processes were also functionally altered in steatotic $\mathrm{IHH}$. We found that lipid accumulation was associated with a threefold increase in the activity of caspase 3, a key mediator of apoptosis, as compared to normal IHH (Figure 4a). In contrast, cellular proliferation, measured by the BrdU in- corporation method, was reduced by 1.5 -fold in steatotic $\mathrm{IHH}$, as compared to control cells (Figure $4 \mathrm{~b}$ ). Together, the combined effects of the increased apoptosis and decreased cell proliferation in steatotic cells were reflected in the $>2$ fold increase in cell death that was observed in cells with steatosis, as shown in Figure $4 \mathrm{c}$ by trypan blue dye exclusion $(8 \% \pm 2.1$ vs $17.5 \% \pm 3.3$ of dead cells in control and steatotic 
Table 2 Biological functions and related gene expression in steatotic immortalized human hepatocytes

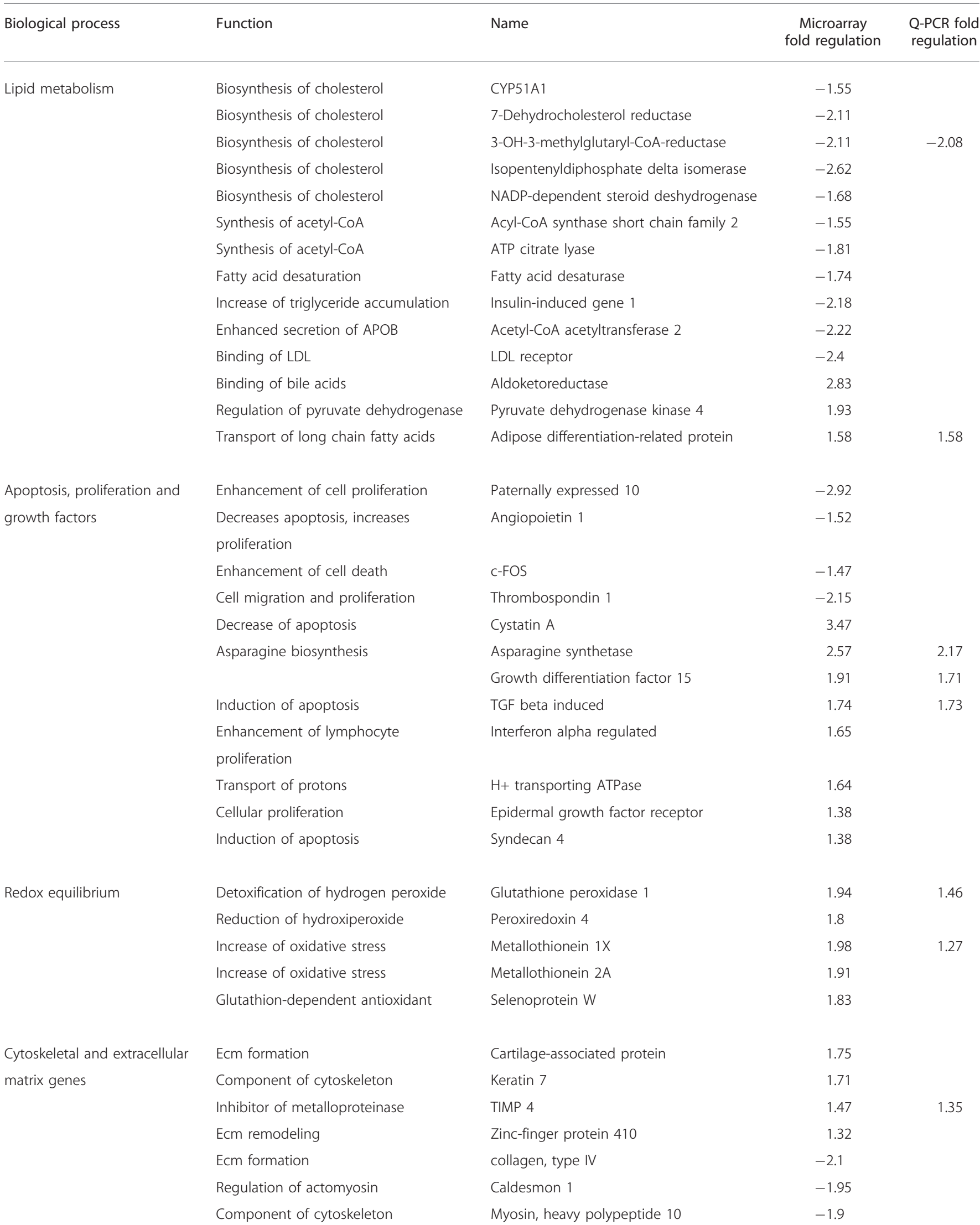


Table 2 Continued

\begin{tabular}{llll}
\hline Biological process & Function & Name & $\begin{array}{r}\text { Microarray } \\
\text { Q-PCR fold } \\
\text { regulation } \\
\text { fold regulation }\end{array}$ \\
& $\begin{array}{l}\text { Cell-to-matrix adhesion } \\
\text { Ecm formation }\end{array}$ & Periplakin & $\begin{array}{r}\text { Collagen type VIII } \\
\text { Coagulation cascade }\end{array}$ \\
& Coagulation factor & Fibrinogen gamma chain & -1.86 \\
& Cofactor of thrombin & Thrombomodulin & 1.73 \\
& Anti-thrombin binding molecule & Syndecan 4 & 1.56 \\
\hline
\end{tabular}

Red characters, upregulation; green characters, downregulation.

See supplementary information online for color version.

IHH, respectively). These data further support IHH as a functionally relevant cellular model to study hepatic steatosis, since they display similar characteristics than fatty liver, ${ }^{35}$ in terms of dysregulation of apoptotic and proliferative mechanisms.

\section{Insulin Signalling in Steatotic IHH}

Lipid accumulation in hepatocytes is often associated with insulin resistance. However, it is unclear whether it is steatosis that can cause insulin resistance or vice versa, and the molecular mechanisms linking these two metabolic defects are poorly defined. Our microarray analysis could not detect changes in the expression of gene associated with the insulin signalling pathway; however, it still remains the possibility that intracellular lipid accumulation modulate the expression of critical factors in the insulin signalling cascade at the posttranscriptional level. To investigate whether steatosis affects insulin signalling pathways in $\mathrm{IHH}$, control and oleic acidtreated IHH were serum starved and stimulated for different times with insulin. Activation of insulin-dependent metabolic and mitogenic signalling was then quantitatively assessed by Western blot. Surprisingly, tyrosine phosphorylations of the insulin receptor and IRS1 in response to insulin were increased in steatotic $v s$ control cells at early time points of the stimulation (Figure $5 \mathrm{a}$ and $\mathrm{b}$ ). On the other hand, phosphorylation of IRS2 was unaffected by steatosis (data not shown). Phosphorylation of IRS1 on negative regulatory serine 636 and 639 residues, which can be triggered by multiple intracellular kinases to downregulate IRS1-PI 3-K signalling, was observed in response to insulin but was unaffected by lipid accumulation (Figure 5b). Consistent with these data, Akt/PKB phosphorylation and ERK1/2 activation were significantly increased in steatotic cells (Figure $5 \mathrm{c}$ and $\mathrm{d}$ ). Levels of protein expression of all signalling effectors tested were similar in control and steatotic cells, consistent with the lack of changes observed with the microarray data. Finally, we tested also by RT-PCR the expression GSK3, FAS and PEPCK, three major genes regulated by insulin and controlling lipid and glucose metabolism, in control and steatotic IHH. GSK3 expression was not affected when cells were incubated with oleic acid to induce steatosis, but the expression of FAS, an enzyme regulating the synthesis of fatty acid, was decreased both in the microarray analysis (2.01-fold) and by RT-PCR (2.56-fold), as expected when cells are overloaded with exogenous fatty acids (Table 2 ). PEPCK expression was below confident detectable levels, both in the microarray analysis and RT-PCR.

These data indicate that triglyceride accumulation in IHH rather to inhibit insulin signalling, has a stimulatory effect on the activation of intracellular cascades initiated by insulin and do not affect significantly expression of insulin-regulated genes controlling glucose metabolism, thus suggesting that oleic acid-induced steatosis in IHH cells is not associated with insulin resistance.

\section{DISCUSSION}

In this study, changes in gene expression associated with the accumulation of intracellular triglycerides, that is, steatosis, were examined in IHH. This new hepatic cell model proved to be of interest to study the expression pattern of genes potentially involved in the development of steatosis. Indeed, in contrast to other commonly used cell types such as Hep G2 or Huh-7, IHH are closer to primary human hepatocytes, since they accumulate lipid droplets only following exposure to fatty acids and not in normal culture conditions. Data indicated that oleic acid-induced steatosis affects the expression of a series of genes involved in the control of apoptosis, cellular proliferation, intracellular redox balance and in the regulation of lipid metabolism. Changes in gene expression associated with steatosis were also correlated with functional alterations of cellular processes implicating these gene products. Finally, while genetic analyses do not indicate major alterations in insulin signalling and resistance, we observed that steatotic cells were more sensitive to insulin, suggesting that steatosis is not associated with insulin resistance in IHH. Together, our results suggest that fatty $\mathrm{IHH}$ 
are an in vitro model, which reliably reproduces some of the biological changes observed in vivo, when liver steatosis develops in the absence of insulin resistance.

Hepatocyte apoptosis is a feature of fatty liver disease, ${ }^{24}$ which is also observed with chronic hepatitis $\mathrm{C}$ infection. ${ }^{36}$
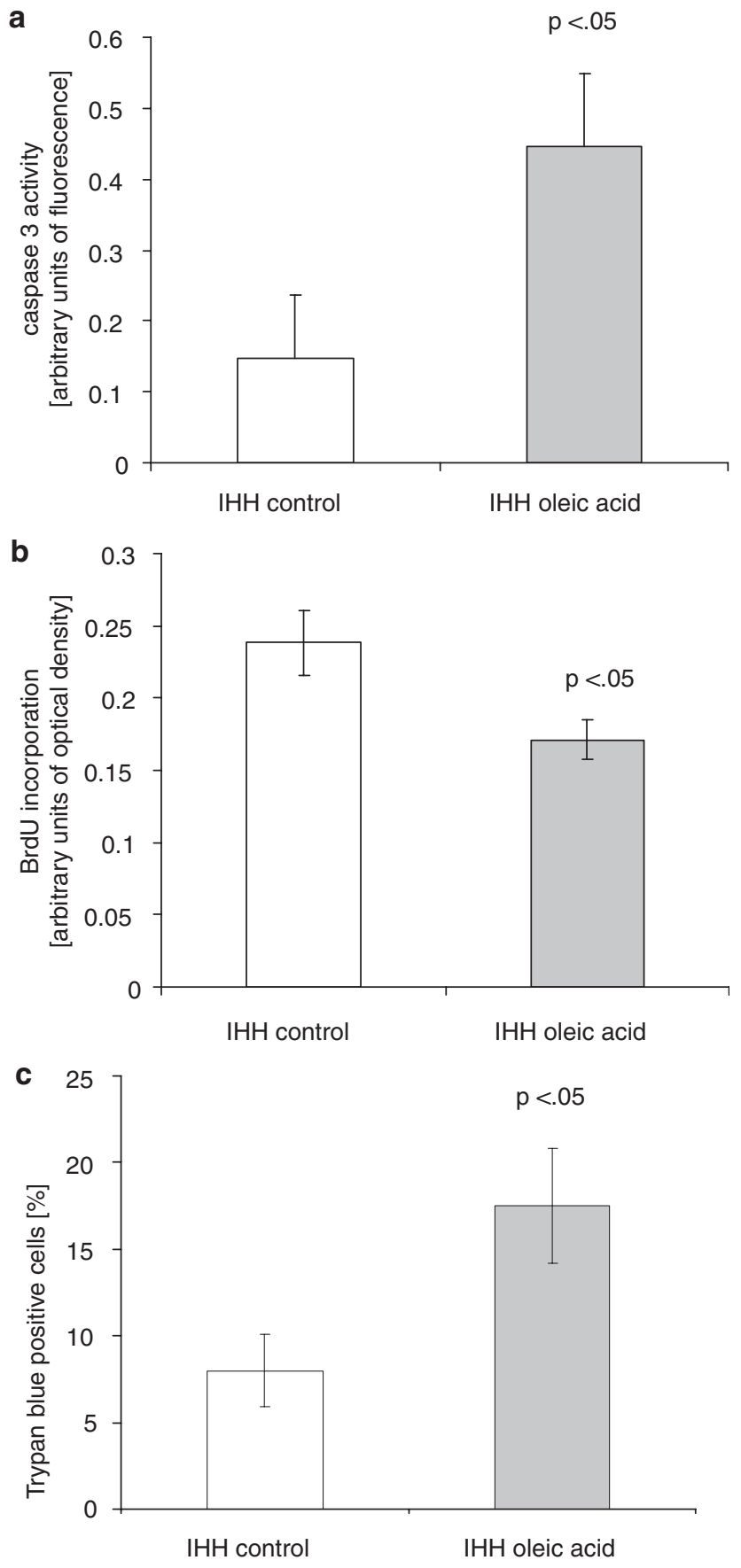

This characteristic is of clinical importance, since fatty infiltration of the liver is associated with increased liver failure rates after hepatectomy or liver transplantation, ${ }^{37,38}$ where cellular regeneration plays a crucial role in the recovery from ischemia-reperfusion damage. In $\mathrm{IHH}$, the development of steatosis, following exposure to oleic acid at the concentration used, was also associated with an increased apoptosis, as assessed by an enhanced caspase 3 activity. Of note, measurement of caspase activity in serum has been recently proposed for the detection of early liver injury in HCV infection. ${ }^{39}$ How apoptosis is regulated in lipid laden tissues is unclear, but an increased production of ceramide has been suggested to be the causative factor. ${ }^{40}$ In our microarray analysis, we could, however, not detect significant changes in the expression of enzymes participating to this process, such as sphingomyelinase or serine-palmitoyl tranferase. In parallel to an increased apoptosis, cellular proliferation resulted inhibited in steatotic $\mathrm{IHH}$, in agreement with other authors reporting a impaired BrdU incorporation in $\mathrm{db} / \mathrm{db}$ mice after partial hepatectomy and no induction of cyclin $\mathrm{D}$ in ob/ob mice after toxic liver injury. ${ }^{41,42}$ A precise mechanism underlying the proliferation defect is not suggested from data of the microarray analysis, since several genes that could potentially favor or prevent proliferation are modulated in steatotic IHH. Thus, the increased apoptosis and the decreased proliferation of fatty hepatocytes are likely the net results of the up- or downregulation of several genes (see also Table 2), which positively or negatively affect both these processes, with the final result of an increased cell death in cells exposed to fatty acids, as we observed in our experiments.

Biochemical analyses of lipid metabolism demonstrated that the triglyceride content and biosynthesis were strongly increased in steatotic $\mathrm{IHH}$, whereas lipogenesis of fatty acids and cholesterol was inhibited. The latter observation strongly correlated with genetic alterations evidenced in our microarray studies, indicating a decreased expression of enzymes involved in cholesterol and fatty acid synthesis, such as HMG-CoA synthase/squalene epoxydase and HMG-CoA

Figure 4 Apoptosis, proliferation and viability in normal and steatotic $\mathrm{HH}$. (a) Apoptosis is increased in steatotic $\mathrm{IHH}$. Apoptosis was quantified with a fluorescence-based caspase 3 activity assay as described in Materials and methods, in IHH under normal conditions or after induction of steatosis with oleic acid. (b) Decreased proliferation of steatotic IHH. Cellular proliferation was measured using a BrdU incorporation assay in control and steatotic $\mathrm{IHH}$, as described in Materials and methods. (c) Cell viability measured by trypan blue exclusion in control and steatotic IHH. Data are means \pm s.d. of three independent experiments.

Figure 5 Insulin-dependent phosphorylation cascades in control and steatotic IHH. Protein expression and phosphorylation of critical insulin effectors mediating the mitogenic and metabolic effects of insulin were quantitatively assessed by Western analyses in IHH exposed or not for 7 days to $50 \mu \mathrm{M}$ oleic acid and stimulated for different times with $10^{-7} \mathrm{M}$ insulin. (a) Expression and phosphorylation of the insulin receptor (IR), (b) expression and phosphorylation of the IRS1 on Tyr632 and Ser636/9, (c) expression and phosphorylation of ERK1/2 and (d) expression and phosphorylation of Akt. Western blots are representative of five independent experiments. Results of the quantifications are expressed as a percentage of control IHH and represent the means \pm s.e. Differences were considered significant when $P<0.05\left(^{*}\right)$ or $P<0.01\left(^{* *}\right)$. 
a

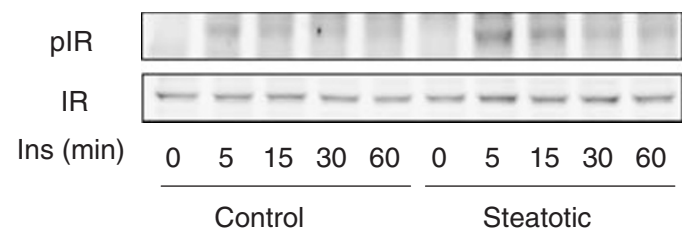

b

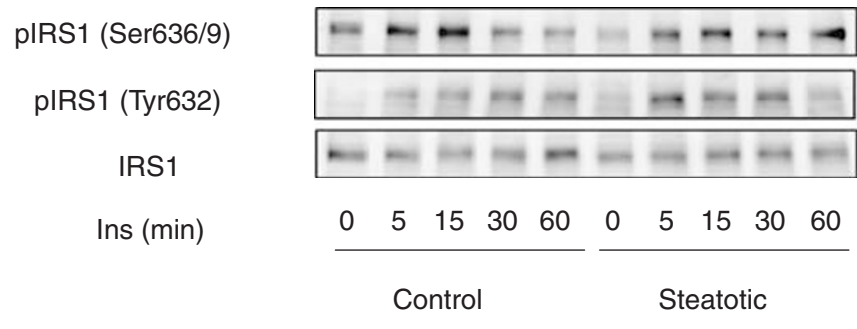

C

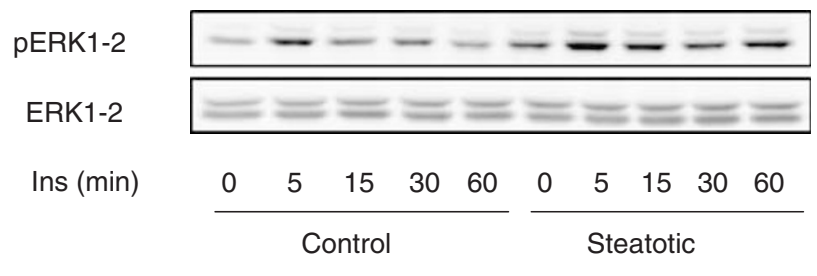

d

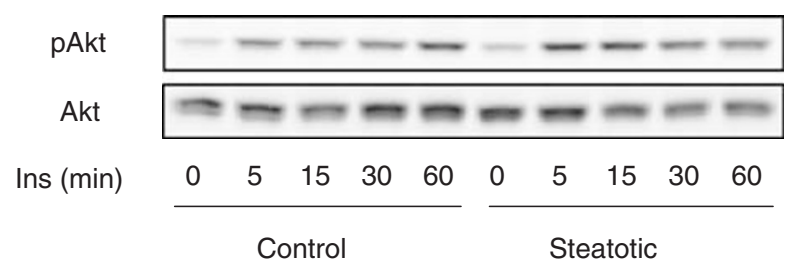

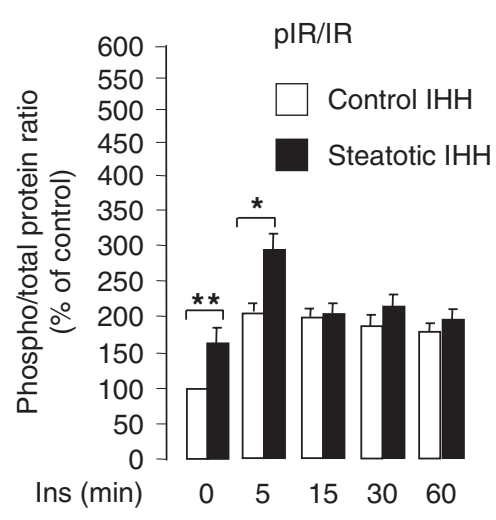
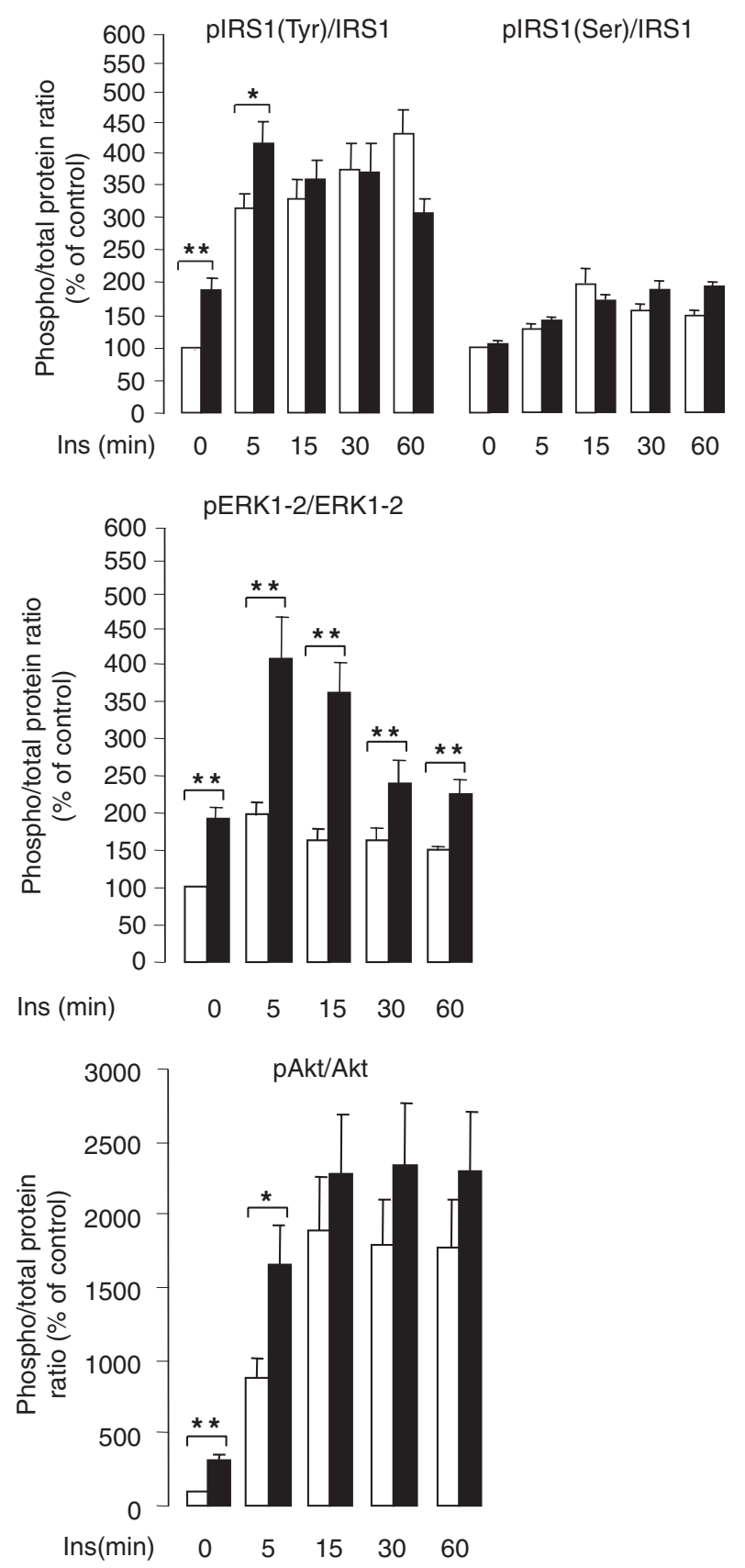
reductase/acetyl-CoA acetyltransferase-2, respectively. However, the expression of genes encoding enzymes regulating the synthesis of triglycerides (glycerolphosphate acyltransferase, acylglycerol-phosphate acyltransferase, acyl-CoA:monoacylglycerol acyltransferase) was not altered in IHH exposed to oleic acid. It is thus likely that the increased triglyceride content in steatotic IHH is not due to a genetic upregulation of enzymes directing these processes. Rather, the enhanced biosynthesis of triglycerides may be caused by the excess of substrate available or by posttranscriptional mechanisms upregulating the activities of key enzymes involved in this process.

Treatment of IHH with oleic acid was followed by an efficient accumulation of intracellular lipids in the form of a prevalently microvesicular steatosis. In contrast to other liver-derived cell lines currently used, such as Hep G2 or Huh-7, IHH were not steatotic in normal culture conditions. This feature has not been identified before in these cells ${ }^{43,44}$ and may represent an important advantage for $\mathrm{IHH}$, due to the fact that steatosis may be induced with oleic acid from real non steatotic cells in control conditions. Moreover, the presence of a spontaneous steatosis in Hep G2 and Huh-7 cells may incorrectly be underestimated by investigators interested in studying lipid metabolism in hepatocytes. Finally, the fact that steatosis is associated with relevant metabolic changes underlines the importance of working with steatosisfree hepatocytes as controls.

In studies from other authors using Hep G2 cells, 'oversteatosis' was induced using higher fatty acid concentrations $(0.5-1 \mathrm{mM})$ for a shorter duration $(24 \mathrm{~h})$, but this was accompanied by an important (10-fold) increase in apoptosis, ${ }^{45}$ which is improbable in an in vivo situation characterized by steatosis in the absence of other lesions, such as inflammation or iron overload. The spontaneous lipid overload in Hep G2 and Huh-7 cells observed with the Oil-red-O staining was confirmed with TLC. As a consequence, our results improve the initial functional evaluation of $\mathrm{IHH}^{30}$ and suggest that this cell line may be more suitable than other hepatocytederived cell lines for in vitro studies focusing on mechanisms of lipid accumulation in the liver.

Previous studies have suggested that a link exists between hepatic fat accumulation and insulin resistance, ${ }^{46,47}$ but the underlying mechanisms linking these two phenomena are yet unclear. ${ }^{48-50}$ This concept is however subject to controversy, with recent studies indicating that fatty liver is not always associated with insulin resistance and that insulin resistance is not a critical factor in the development of hepatic steatosis. ${ }^{17-19}$ With respect to a potential role of insulin resistance in the development of steatosis, a decreased expression of IRS and posttranscriptional phosphorylation on serine residues of these effectors have been suggested to play a key role in hepatic insulin resistance. ${ }^{51-53}$ Knocking down IRS1 or IRS2 in the liver of mice has been shown to have distinct consequences in hepatocytes: depletion of IRS1 caused an increase in gluconeogenesis, whereas IRS2 knockdown upregulated lipogenic enzymes. ${ }^{23}$ In the same study, mice knocked down for both IRS1 and 2 displayed also hepatic steatosis. In contrast, another report indicated that specific IRS2 knockdown in the liver in mice already systemically devoid of IRS1 $\left(\operatorname{Irs} 1^{-1-}\right.$ ), did not induce a fatty liver, but, surprisingly, a significant decrease in the content of liver triglycerides. ${ }^{54}$ Thus, it is still unclear how IRS alterations in their expression and activity impact the lipid metabolism and the occurrence of steatosis. Our genetic and biochemical analyses could neither detect changes in the expression of IRS proteins nor in the several other proteins associated with the insulin signalling pathways and insulin resistance that we have tested. This suggests that intracellular lipid accumulation does not significantly modulate the expression of major insulin signalling effectors in this cell model. In contrast, activation of insulin signalling effectors mediating both mitogenic and metabolic effects of insulin was increased in $\mathrm{IHH}$ exposed to oleic acid, indicating that insulin signalling, and likely insulin sensitivity of these cells, was increased in steatosis. Our data are thus in support of the concept that insulin resistance and steatosis are not strictly associated in hepatocytes, and that other metabolic factors might be involved in their frequent association. IHH might thus represent a valuable in vitro model for further studies aiming at clarifying the above conceptual issues.

One recent study profiled mRNA responses in Huh-7 cells after exposure to palmitate. ${ }^{55}$ We showed that Huh-7 cells are per se steatotic and are probably not the best model to investigate the gene expression profile after treatment with an inducer of steatosis. Despite additional differences with the present work, such as the short-term exposure $(48 \mathrm{~h} v s \quad 7$ days) and the different microarrays used (18000 sequences $v s$ 57000 ), some important similar findings still emerge. Indeed, the increased expression of lipid transport and metabolism genes, the upregulation of oxidative stress response genes and the inhibition of cellular growth were characteristic of both models. In contrast with the data obtained with Huh-7 cells, some cytoskeletal and extracellular matrix genes, such as keratin 7 , and syndecan 4 resulted in being upregulated in our model, possibly due to the different durations of treatment.

The issue of global gene expression in steatosis and nonalcoholic steatohepatitis has been addressed in human liver biopsies, ${ }^{27-29}$ emphasizing the impaired capacity for dismutation of reactive oxygen species. Similar findings in our study indicated that several of the differentially expressed genes were involved in the regulation of oxidative metabolism. However, in contrast with the results from liver biopsies, genes involved in inflammation and fibrosis, such as TGFbeta and IL-1R, were not significantly dysregulated in our model. This is possibly due to the fact that hepatocytes only were the material for our analyses, while liver biopsies also contain other liver cells, such as Kupffer cells, myofibroblasts, endothelial cells or polymorphonuclear cells.

In summary, the data obtained in this novel IHH-based model of steatosis from the microarray analyses are 
supported by the biochemical measurements and suitably reproduce the features of fatty liver observed in vivo. These results may represent the basis for further studies to investigate the mechanisms and the consequences of lipid accumulation in hepatocytes.

Supplementary Information accompanies the paper on the Laboratory Investigation website (http://www.laboratoryinvestigation.org)

\section{ACKNOWLEDGEMENTS}

The authors kindly acknowledge P Descombes, C Delucinge and C Barraclough for their expert assistance and criticism in microarray and PCR experiments. Sources of support: this work was supported by a grant from the Foundation for Liver and Gut Studies (FLAGS) in Geneva to ADG, grants from Novo Nordisk A/S (Denmark) and from the Swiss National Science Foundation \# 3100A0-104489 to MF and a grant from the Sir Jules Thorn Overseas Charitable Trust, Geneva.

\section{DUALITY OF INTEREST}

None declared.

1. Clark JM, Brancati FL, Diehl AM. Nonalcoholic fatty liver disease. Gastroenterology 2002;122:1649-1657.

2. Harrison SA, Diehl AM. Fat and the liver-a molecular overview. Semin Gastrointest Dis 2002;13:3-16.

3. Mager DR, Roberts EA. Nonalcoholic fatty liver disease in children. Clin Liver Dis 2006;10:109-131, vi-vii.

4. Day CP, James OF. Hepatic steatosis: innocent bystander or guilty party? Hepatology 1998;27:1463-1466.

5. Castera L, Hezode C, Roudot-Thoraval F, et al. Worsening of steatosis is an independent factor of fibrosis progression in untreated patients with chronic hepatitis C and paired liver biopsies. Gut 2003;52: 288-292.

6. Westin $\mathrm{J}$, Nordlinder $\mathrm{H}$, Lagging $\mathrm{M}$, et al. Steatosis accelerates fibrosis development over time in hepatitis C virus genotype 3 infected patients. J Hepatol 2002;37:837-842.

7. Hickman IJ, Clouston AD, Macdonald GA, et al. Effect of weight reduction on liver histology and biochemistry in patients with chronic hepatitis C. Gut 2002;51:89-94.

8. Adams LA, Lymp JF, St Sauver J, et al. The natural history of nonalcoholic fatty liver disease: a population-based cohort study. Gastroenterology 2005;129:113-121.

9. Ratziu V, Bonyhay L, Di Martino V, et al. Survival, liver failure, and hepatocellular carcinoma in obesity-related cryptogenic cirrhosis. Hepatology 2002;35:1485-1493.

10. Bradbury MW. Lipid metabolism and liver inflammation. I. Hepatic fatty acid uptake: possible role in steatosis. Am J Physiol Gastrointest Liver Physiol 2006;290:G194-G198.

11. Charlton M, Sreekumar R, Rasmussen D, et al. Apolipoprotein synthesis in nonalcoholic steatohepatitis. Hepatology 2002;35:898-904.

12. Letteron $P$, Sutton A, Mansouri A, et al. Inhibition of microsomal triglyceride transfer protein: another mechanism for drug-induced steatosis in mice. Hepatology 2003;38:133-140.

13. Lonardo A, Adinolfi LE, Loria $P$, et al. Steatosis and hepatitis $C$ virus: mechanisms and significance for hepatic and extrahepatic disease. Gastroenterology 2004;126:586-597.

14. Robertson G, Leclercq I, Farrell GC. Nonalcoholic steatosis and steatohepatitis. II. Cytochrome P-450 enzymes and oxidative stress. Am J Physiol Gastrointest Liver Physiol 2001;281:G1135-G1139.

15. Galli A, Svegliati-Baroni G, Ceni E, et al. Oxidative stress stimulates proliferation and invasiveness of hepatic stellate cells via a MMP2-mediated mechanism. Hepatology 2005;41:1074-1084.

16. Chitturi S, Abeygunasekera S, Farrell GC, et al. NASH and insulin resistance: Insulin hypersecretion and specific association with the insulin resistance syndrome. Hepatology 2002;35:373-379.

17. Guidorizzi de Siqueira AC, Cotrim HP, Rocha R, et al. Non-alcoholic fatty liver disease and insulin resistance: importance of risk factors and histological spectrum. Eur J Gastroenterol Hepatol 2005;17:837-841.
18. Lonardo A, Lombardini S, Scaglioni F, et al. Hepatic steatosis and insulin resistance: does etiology make a difference? J Hepatol 2006:44:190-196.

19. Matsumoto M, Han S, Kitamura $T$, et al. Dual role of transcription factor FoxO1 in controlling hepatic insulin sensitivity and lipid metabolism. J Clin Invest 2006;116:2464-2472.

20. Azzout-Marniche D, Becard D, Guichard C, et al. Insulin effects on sterol regulatory-element-binding protein-1c (SREBP-1c) transcriptional activity in rat hepatocytes. Biochem J 2000;350(Part 2):389-393.

21. Browning JD, Horton JD. Molecular mediators of hepatic steatosis and liver injury. J Clin Invest 2004;114:147-152.

22. Matsumoto M, Ogawa W, Teshigawara $\mathrm{K}$, et al. Role of the insulin receptor substrate 1 and phosphatidylinositol 3-kinase signaling pathway in insulin-induced expression of sterol regulatory element binding protein $1 \mathrm{c}$ and glucokinase genes in rat hepatocytes. Diabetes 2002;51:1672-1680.

23. Taniguchi CM, Ueki K, Kahn R. Complementary roles of IRS-1 and IRS-2 in the hepatic regulation of metabolism. J Clin Invest 2005;115: 718-727.

24. Feldstein $A E$, Canbay $A$, Angulo $P$, et al. Hepatocyte apoptosis and fas expression are prominent features of human nonalcoholic steatohepatitis. Gastroenterology 2003;125:437-443.

25. Walsh MJ, Vanags DM, Clouston AD, et al. Steatosis and liver cell apoptosis in chronic hepatitis C: a mechanism for increased liver injury. Hepatology 2004;39:1230-1238.

26. Roskams T, Yang SQ, Koteish A, et al. Oxidative stress and oval cell accumulation in mice and humans with alcoholic and nonalcoholic fatty liver disease. Am J Pathol 2003;163:1301-1311.

27. Chiappini F, Barrier A, Saffroy R, et al. Exploration of global gene expression in human liver steatosis by high-density oligonucleotide microarray. Lab Invest 2006;86:154-165.

28. Sreekumar R, Rosado B, Rasmussen D, et al. Hepatic gene expression in histologically progressive nonalcoholic steatohepatitis. Hepatology 2003;38:244-251.

29. Younossi ZM, Baranova A, Ziegler K, et al. A genomic and proteomic study of the spectrum of nonalcoholic fatty liver disease. Hepatology 2005;42:665-674.

30. Nguyen TH, Mai G, Villiger $P$, et al. Treatment of acetaminopheninduced acute liver failure in the mouse with conditionally immortalized human hepatocytes. J Hepatol 2005;43: 1031-1037.

31. Peirson SN, Butler JN, Foster RG. Experimental validation of novel and conventional approaches to quantitative real-time PCR data analysis. Nucleic Acids Res 2003;31:e73.

32. Folch J, Ascoli I, Lees $M$, et al. Preparation of lipide extracts from brain tissue. J Biol Chem 1951;191:833-841.

33. Bligh EG, Dyer WJ. A rapid method of total lipid extraction and purification. Can J Biochem Physiol 1959;37:911-917.

34. Kleiner DE, Brunt EM, Van Natta M, et al. Design and validation of a histological scoring system for nonalcoholic fatty liver disease. Hepatology 2005;41:1313-1321.

35. Wieckowska A, Zein NN, Yerian LM, et al. In vivo assessment of liver cell apoptosis as a novel biomarker of disease severity in nonalcoholic fatty liver disease. Hepatology 2006;44:27-33.

36. Farinati $F, C$ ardin $R$, Bortolami $M$, et al. The mechanisms underlying hepatitis $C$ virus genotype 3-mediated liver damage. J Hepatol 2003;39:292-294.

37. Selzner M, Clavien PA. Failure of regeneration of the steatotic rat liver: disruption at two different levels in the regeneration pathway. Hepatology 2000;31:35-42.

38. Yang SQ, Lin HZ, Mandal AK, et al. Disrupted signaling and inhibited regeneration in obese mice with fatty livers: implications for nonalcoholic fatty liver disease pathophysiology. Hepatology 2001;34:694-706.

39. Bantel H, Lugering A, Heidemann J, et al. Detection of apoptotic caspase activation in sera from patients with chronic HCV infection is associated with fibrotic liver injury. Hepatology 2004;40: 1078-1087.

40. Unger RH, Orci L. Lipoapoptosis: its mechanism and its diseases. Biochim Biophys Acta 2002;1585:202-212.

41. Leclercq IA, Field J, Farrell GC. Leptin-specific mechanisms for impaired liver regeneration in ob/ob mice after toxic injury. Gastroenterology 2003:124:1451-1464. 
42. Uetsuka K, Shirai M, Yamauchi $H$, et al. Impaired proliferation of nonparenchymal cells participates in an impairment of liver regeneration in db/db mice. Exp Mol Pathol 2005;79:51-58.

43. Masuda $\mathrm{Y}$, Itabe $\mathrm{H}$, Odaki $\mathrm{M}$, et al. Adipose differentiation-related protein is degraded through the proteasome-dependent pathway during regression of lipid-storing cells. J Lipid Res 2005;47: 87-98.

44. Okamoto Y, Tanaka S, Haga Y. Enhanced GLUT2 gene expression in an oleic acid-induced in vitro fatty liver model. Hepatol Res 2002;23: 138-144.

45. Feldstein AE, Werneburg NW, Canbay A, et al. Free fatty acids promote hepatic lipotoxicity by stimulating TNF-alpha expression via a lysosomal pathway. Hepatology 2004;40:185-194.

46. Adams LA, Angulo P. Recent concepts in non-alcoholic fatty liver disease. Diabet Med 2005;22:1129-1133.

47. Bugianesi E, McCullough AJ, Marchesini G. Insulin resistance: a metabolic pathway to chronic liver disease. Hepatology 2005;42: 987-1000.

48. Marchesini G, Brizi M, Morselli-Labate AM, et al. Association of nonalcoholic fatty liver disease with insulin resistance. Am J Med 1999;107:450-455.
49. Samuel VT, Liu ZX, Qu X, et al. Mechanism of hepatic insulin resistance in non-alcoholic fatty liver disease. J Biol Chem 2004;279:32345-32353.

50. Sanyal AJ, Campbell-Sargent C, Mirshahi F, et al. Nonalcoholic steatohepatitis: association of insulin resistance and mitochondrial abnormalities. Gastroenterology 2001;120:1183-1192.

51. Shimomura I, Matsuda M, Hammer RE, et al. Decreased IRS-2 and increased SREBP-1c lead to mixed insulin resistance and sensitivity in livers of lipodystrophic and ob/ob mice. Mol Cell 2000;6:77-86.

52. Sun Y, Liu S, Ferguson S, et al. Phosphoenolpyruvate carboxykinase overexpression selectively attenuates insulin signaling and hepatic insulin sensitivity in transgenic mice. J Biol Chem 2002;277: 23301-23307.

53. Thirone AC, Huang C, Klip A. Tissue-specific roles of IRS proteins in insulin signaling and glucose transport. Trends Endocrinol Metab 2006;17:72-78.

54. Dong X, Park S, Lin X, et al. Irs1 and Irs2 signaling is essential for hepatic glucose homeostasis and systemic growth. J Clin Invest 2006;116:101-114.

55. Swagell CD, Henly DC, Morris CP. Expression analysis of a human hepatic cell line in response to palmitate. Biochem Biophys Res Commun 2005;328:432-441. 